\title{
CONTRIBUIÇÕES PEDAGÓGICAS DAS PRÁTICAS LÚDICAS NO DESENVOLVIMENTO INFANTIL
}

\author{
PEDAGOGICAL CONTRIBUTIONS OF PLAYING PRACTICES IN CHILD DEVELOPMENT
}

\author{
Roseli da Cruz Brandoni \\ Prefeitura Municipal de Barra do Bugres, Mato Grosso, MT, Brasil. E-mail: roselibrandoni@gmail.com
}

DOI: https://doi.org/10.46550/amormundi.v2i7.134

Recebido em: 10.11.2021

Aceito em: 24.12.2021

\begin{abstract}
Resumo: Este artigo discorre acerca das contribuiçóes da ludicidade para o processo de aprendizagem do aluno na etapa da Educaçáo Infantil e apresenta resultados de uma pesquisa qualitativa, cujo objetivo tratou de discutir sobre a importância do brincar no processo de desenvolvimento da criança, visando à construção do conhecimento e aprendizagem por meio de brincadeiras, jogos e brinquedos. Pois, é no brincar que surge a interação entre a espontaneidade e a criatividade com a progressiva aceitação das regras sociais e morais por parte do educando. É brincando que a criança se humaniza, aprendendo a conciliar de forma afetiva a afirmação de si mesma à criação de vínculos afetivos duradouros. Realizou-se um levantamento frente às possibilidades que a brincadeira desencadeia na construção e reconstrução dos conhecimentos, desse modo, contribuindo para elencar as contribuiçóes da ludicidade no processo de ensino-aprendizagem. Desse modo, o lúdico permite novas maneiras de ensinar, associado a fatores que podem tornar o ensino mais atrativo e contribuir com uma educaçáo de maior qualidade, capaz de ir ao encontro dos interesses essenciais à criança. $\mathrm{Na}$ intençấo de viabilizar o desenvolvimento dessa pesquisa, utilizou-se como referências bibliográficas Vygotsky (1984); Kishimoto (2003); Base Nacional Comum Curricular (2017) e ainda outros autores que versam sobre a temática da ludicidade na infância.
\end{abstract}

Palavras-chave: Ludicidade. Jogos e Brincadeiras. Aprendizagem.

Abstract: This article discusses the contributions of playfulness to the student's learning process in the Early Childhood Education stage and presents the results of a qualitative research, whose objective was to discuss the importance of playing in the child's development process, aiming at the construction of knowledge and learning through play, games and toys. For, it is in playing that the interaction between spontaneity and creativity emerges, with the student's progressive acceptance of social and moral rules. It is by playing that the child becomes human, learning to affectively reconcile self-affirmation with the creation of lasting affective bonds. A survey was carried out regarding the possibilities that play triggers in the construction and reconstruction of knowledge, thus contributing to list the contributions of playfulness in the teaching-learning process. In this way, playfulness allows for new ways of teaching, associated with factors that can make teaching more attractive and contribute to higher quality education, capable of meeting the essential interests of the child. In order to facilitate the development of this research, we used as bibliographical references Vygotsky (1984); Kishimoto (2003); Common National Curriculum Base (2017) and other authors who deal with the theme of playfulness in childhood.

Keywords: Playfulness. Games and Pranks. Learning. 


\section{Introduçáo}

brincar é uma forma de expressão e comunicação do indivíduo consigo mesmo, com o outro e com o meio. De forma universal, a brincadeira é considerada uma atividade que assume características peculiares no contexto social, histórico e cultural, otimizando o processo educacional de maneira descontraída e organizada pela própria criança em todas as suas interaçôes. $\mathrm{O}$ brincar possibilita o desenvolvimento, não sendo exclusivamente um instrumento didático facilitador para o aprendizado, visto que influencia em áreas do desenvolvimento infantil como: motricidade, inteligência, sociabilidade, afetividade e criatividade.

Além disso, a capacidade de brincar propicia à criança o conhecimento de forma natural e agradável, como meio de estimular a socialização, possibilitando que o indivíduo aja de forma mais autônoma. Por conta disso, as propostas pedagógicas desenvolvidas em sala de aula devem oferecer sugestóes sólidas de instrução, preocupando-se em proporcionar um ensino de qualidade, elevando assim, a capacidade da criança em compreender o universo do qual faz parte, os valores sociais, econômicos e culturais intrínsecos na formação pessoal e profissional ao qual estaráo submetidos.

Considerando a possibilidade de aprendizagem por meio de recursos pedagógicos, fala-se com entusiasmo sobre a inserção de práticas lúdicas nas propostas de ensino. Isso se dá porque atribuiu-se à essa ferramenta prática um valor educacional capaz de potencializar os objetivos básicos da escola, que se refere a transformar uma sociedade, promover cidadania, habilidades e competências, com plena condição de ensino e capacitação para vida pessoal, social e profissional do indivíduo, desde a sua infância.

Portanto, a discussão dessa temática se mostra perspicaz uma vez que demonstra a dialética das práticas lúdicas no contexto educacional, evidenciando como os processos educacionais podem ser positivamente afetados, conduzindo o educando a ampliar suas capacidades e habilidades de aprendizagem. Promovendo, além de tudo, que a criança desenvolva sua criatividade e interação com o meio, vínculos afetivos duradouros, percepção de valor e plena consciência dos seus atos, responsabilizando-se por tais.

\section{Metodologia}

Sem dúvida, a metodologia do estudo é um elemento essencial na elaboração, diagnóstico e desenvolvimento de uma pesquisa, isso porque viabiliza a construção e organização de conceitos que permitem encarar de maneira distinta um determinado assunto através de métodos científicos. Sobre isso, é importante comentar que o percurso metodológico é um elemento fundamental para a sustentação de qualquer pesquisa científica. É o que permite que o pesquisador seja capaz de situar seu problema e suas inquietaçóes no âmbito das áreas de saber onde estão inseridas.

Logo, "a pesquisa é uma atividade voltada para solução de problemas, através do emprego de processos científicos” (SANTOS, 2000, p. 159). Um desses processos de pesquisa é o exploratório, que se caracteriza por uma averiguação quanto ao assunto que se quer investigar. "A pesquisa exploratória configura-se como a que acontece na fase preliminar do trabalho [...] com o objetivo de levantar maiores informaçóes sobre o assunto que será investigado" (PRESTES, 2003, p. 26). 
Desse modo, o estudo exploratório ocorre sobre uma indagação de pesquisa em que comumente há poucas discussões anteriores a seu respeito, buscando sempre novas informaçóes quanto ao assunto central do trabalho. Além disso, a pesquisa exploratória avalia quais teorias existentes podem ser aplicadas no objeto de estudo para que o problema diagnosticado seja resolvido do ponto de vista científico e/ou acadêmico.

Portanto, a metodologia utilizada nessa produção corresponde à pesquisa bibliográfica por conta da fundamentação teórica que se construiu para discutir as informaçôes levantadas e apresentadas ao longo do artigo. Assim, no primeiro momento o artigo se norteia por meio da revisão bibliográfica construída ao desenrolar da sua aplicação na unidade escolar. Na intenção de viabilizar o desenvolvimento dessa pesquisa, utilizou-se como referências bibliográficas Vygotsky (1984); Kishimoto (2003); Base Nacional Comum Curricular (2017) e ainda outros autores que versam sobre a temática da ludicidade na infância.

\section{Referencial teórico}

\subsection{A ludicidade e a aprendizagem}

A ludicidade como recurso pedagógico, proporciona à criança momentos em que ela pode mostrar sua agilidade por meio da competição, refletir sobre o fazer, organizar e desorganizar, construir e reconstruir, crescer nos aspectos culturais e sociais como parte essencial de uma sociedade. E, as práticas lúdicas favorecem o desenvolvimento de diversas habilidades, além das motoras. Desse modo, é indispensável proporcionar ao aluno um ambiente propício às práticas lúdicas e, assim, explorar atividades para desenvolver as habilidades do aluno.

Por isso, se diz que as práticas lúdicas enquanto recurso pedagógico incentivam o processo de desenvolvimento infantil. Dessa forma, afirma-se que a ludicidade oportuniza o processo de aprendizagem como um todo, visto que as crianças aprendem a colaborar umas com as outras, combinando e respeitando as devidas fases, conforme a proposta lúdica. Nesse sentido, Brougère (1998) acredita que o brincar instiga ao processo de aprendizagem, para além da sala de aula.

Sobre isso, Fortuna (2003) comenta que o lúdico auxilia na construção do conhecimento infantil e promove segurança para a criança expressar sentimentos e desejos. Proporcionando, assim, a possibilidade de que o profissional docente aperfeiçoe os meios didáticos utilizados em sala de aula. Por isso, RIZZO (2001, p. 40) diz que "a atividade lúdica pode ser um eficiente aliado ao educador interessado no desenvolvimento da inteligência de seus alunos, quando mobiliza sua ação intelectual."

É por conta desse aspecto que as práticas lúdicas não devem ser encaradas somente como atividade educacional em face única da criança, mas também, como indicador de aprendizagem e conhecimento ao ser utilizado. Além disso, é preciso que se reconheça o valor da ludicidade no desenvolvimento da criança, visando a ludicidade como caminho para uma aprendizagem significativa e a construçáo do conhecimento de maneira integral.

Ainda, cabe trazer à discussão que, além de desenvolver capacidades físicas e motoras, a educação por meio do brincar deve assumir a tarefa de agregar e incorporar o aluno na cultura corporal do movimento, tornando-o capaz de compreender os aspectos técnicos e táticos. No caso de uma atividade coletiva, por exemplo, a criança deve saber como praticar, aplicar as regras 
básicas e saber conviver com o adversário, pois, sem ele, a prática lúdica não seria possível.

Assim, percebe-se que, no contexto escolar, o lúdico não deve estar limitado apenas ao desenvolvimento de suas açôes práticas. Para Darido (2003), dentro do conteúdo, a dimensão histórica, a técnica, as habilidades motoras, quando levadas à prática de maneira organizada e proposital, contribuem positivamente para a vida do aluno. E, além dessa contribuição, a ludicidade permite a vivência de inúmeras práticas corporais e de integração social e cultural entre aqueles que se sujeitam às propostas.

De acordo ainda com Kishimoto (2003), o lúdico permite à criança construir a sua autonomia, sua personalidade e ainda desenvolver a linguagem. Maluf (2003) afirma que o brincar é algo essencial, porque é assim que o indivíduo aflora sua criatividade e capacidade de socializar. Por isso, o brincar é visto como um recurso pedagógico que garante manter a criança conectada com a realidade. E, isso está em consonância com o maior objetivo da Educação Infantil, que é promover a troca e a interação da criança interaja com o mundo real, ao mesmo tempo em que se sente livre para brincar, observar e construir seu conhecimento.

Além do mais, conforme Vygotsky (1984), o ato de brincar proporciona um suporte para as mudanças das necessidades e da consciência da criança. Sendo assim, a atuação do aluno no âmbito da imaginação, em dada situação imaginária, oportuniza a criação de intençóes voluntárias e a formação dos planos da vida real e das motivaçôes da vontade. Neste sentido, tudo surge ao brincar, o que se constitui no mais alto nível de desenvolvimento da criança, e é somente nessa dimensáo que a brincadeira pode ser considerada uma atividade condutora que, de fato, determina o desenvolvimento do indivíduo.

Outrossim, Santin (1994, p. 03) salienta que a ludicidade promove "açóes vividas e sentidas, não definíveis por palavras, mas compreendidas pela fruição, povoadas pela fantasia, pela imaginação e pelos sonhos que se articulam com materiais simbólicos”. Desse modo, é possível afirmar que a ludicidade proporciona um desenvolvimento sadio e harmonioso, sendo uma tendência instintiva da criança. Portanto, ao brincar o indivíduo aumenta a independência, estimula sua sensibilidade visual e auditiva, valoriza sua cultura, desenvolve habilidades motoras, exercita a imaginação e a criatividade, aprimora a inteligência emocional, aumenta a integração, promovendo assim, o desenvolvimento sadio, o crescimento mental e a adaptaçáo social.

\subsection{Contribuiçóes das práticas lúdicas no contexto educacional}

A Base Nacional Comum Curricular (2017), normatiza que toda criança tem o direito de se desenvolver de maneira plena, contemplando as etapas que compóem a formação cidadã em seus aspectos intelectual, social e emocional. E, uma das maneiras de se garantir esse pleno desenvolvimento é por meio de atividades que vão de encontro às necessidades das crianças. Nesse sentido, destaca-se a importância de uma proposta didático-pedagógica que apresente reflexôes direcionadas ao universo infantil, definindo-se estratégias adequadas à aprendizagem da criança.

Entáo, se diz que por meio das atividades lúdicas as crianças aprendem a compartilhar objetos e brinquedos, a superar o seu egoísmo, expor seus desejos e solucionar os conflitos que surgem através das interações. Por isso, se faz necessário que haja fomentação e diversificação nas propostas educacionais, oferecendo ideias que despertem o interesse e participação da criança, além de contribuir significativamente para o seu desenvolvimento nos aspectos físicos e motores. 
Com isso, percebe-se que as práticas lúdicas promovem a aprendizagem dos conteúdos, e assimilação de situaçóes reais, desenvolvendo o pensamento e levando a uma participação ativa da criança. Por isso, são fundamentais para o aluno em processo de aprendizagem. Esta ideia se relaciona com a afirmação de Vygotsky (1989) de que o desenvolvimento do sujeito é influenciado pelo meio cultural e pelas condiçôes sociais em que está inserido influencia. Assim, quando orientados e mediados, a utilização de atividades lúdicas contribui para o desenvolvimento de múltiplas habilidades dos alunos.

Nesse sentido, Grando (2000, p. 44) acrescenta que:

Situações que propiciem à criança uma reflexão e análise do seu próprio raciocínio, que esteja 'fora' do objeto, nos níveis já representativos, necessitam ser valorizadas no processo de ensino-aprendizagem [...] demonstra ser um instrumento importante na dinamização do processo [educacional].

Em outras palavras, é possível afirmar que a utilização de recursos lúdicos possibilitam que a criança sinta maior interesse no processo de ensino-aprendizagem, isso porque ela passa a se sentir atraída pela maneira dinâmica e descontraída com que as atividades, geralmente, são propostas, e a partir disso, o educando consegue aprender com prazer, alegria e entretenimento. Ainda, as práticas lúdicas revelam o modo como a criança constitui sua realidade, lida com os possíveis conflitos e as diversas alternativas em seu meio. Além disso, o lúdico introduz o caminho acerca do processo de ensino-aprendizagem, possibilitando a construção da reflexão, autonomia e criatividade da criança.

"A conduta de viver de modo lúdico situaçôes do cotidiano amplia as oportunidades não só de compreensão das próprias experiências como também de progressos do pensamento" (SEBER, 1995, p. 55). Desse modo, propor a aprendizagem por meio de atividades lúdicas, pode instigar na criança o ávido interesse em aprender coisas novas e significativas para sua formaçáo. Logo, a ludicidade enriquece a identidade da criança, porque ela experimenta outra forma de ser e de pensar; amplia suas concepçóes sobre as coisas e as pessoas, representando uma forma de expressão livre pela qual a criança se torna capaz de expressar sentimentos e manifestá-los.

Nesse respeito, Moyles (2002, p. 33) ressalta que "a maior aprendizagem está na oportunidade oferecida à criança de aplicar algo da atividade lúdica em alguma situaçáo cotidiana”. Por isso, o brincar é um meio em que todos, consequentemente, se divertem, aprendem, socializam, comunicam, trocam experiências, desafiam uns aos outros e interagem, gradativamente, com o mundo ao seu redor. Ou seja, "o brincar é uma parcela importante na vida da criança, por meio da qual se adquire experiência” (SOMMERHALDER, 2011, p.27).

Sendo assim, o brincar proporciona à criança a capacidade de expressar a sua personalidade e a sua vida, ao imitar situaçóes reais do seu cotidiano, nas brincadeiras. A criança interage com o próximo, estabelecendo relaçóes, aprendendo a compreender e a respeitar os limites do outro e a se desenvolver de forma espontânea, sendo capaz de desenvolver as suas habilidades e aprendizagem de forma eficaz ao passar por situações de brincadeiras.

Portanto, a inserção das práticas lúdicas na etapa da Educação Infantil é considerado como um caminho para a aprendizagem e a construção do conhecimento, merecendo, assim, pleno reconhecimento e atenção à inserção de tais práticas ao longo do processo educacional, uma vez que provoca, induz e permite que a criança sinta-se confortável para aprender. 
Sem dúvida, o brincar é uma ação espontânea da criança que promove a construção do conhecimento durante seus atos. Por isso fica evidente que as práticas lúdicas instigam as percepçóes da criança podendo ser provocadas a ponto de gerar o interesse pela aprendizagem constante. Nesse caso, se diz que a ludicidade é um recurso inigualável que, se adequadamente explorado em sala de aula, pode proporcionar diversas experiências à criança, uma vez que por meio do brincar ela se sente motivada a se expressar com maior liberdade e sensibilidade. E é nesse momento prazeroso que o aluno deixa transparecer aspectos relacionados à sua personalidade, bem como situaçôes vivenciadas dentro e fora do ambiente escolar.

Logo, a ludicidade constitui-se como elemento básico que deve ser incentivado e amplamente utilizado nas propostas educativas, e que visam a produção do saber de maneira natural e despretensiosa, desenvolvendo habilidades, descobrindo a si mesmo, refletindo sobre a realidade e a cultura em que se vive e explorando o universo da criatividade e imaginação. Com isso, a incorporação do brincar na prática pedagógica visa desenvolver açóes que contribuam para as múltiplas fases da aprendizagem infantil.

Consequentemente, pode-se dizer que é ao brincar que a criança aumenta a independência, estimula sua sensibilidade visual e auditiva, valoriza sua cultura, desenvolve habilidades motoras, aprimora a inteligência emocional e amplia a integração, promovendo assim, o desenvolvimento sadio, o crescimento mental e a adaptação social. Por isso, assevera-se que o lúdico é o recurso pedagógico pelo qual torna-se possível atribuir qualidade ao processo de ensino e aprendizagem, focando nas necessidades da criança, e criando nela o interesse por descobrir o mundo a sua volta e explorar habilidades individuais.

Portanto, afirma-se que ao introduzir e/ou ampliar as práticas lúdicas na vivência escolar, é possível perceber resultados significativos e duradouros, capazes de promover inúmeras reflexôes sobre a individualidade e as necessidades emocionais, intelectuais e sociais de um indivíduo em formação. Sendo assim, pensar em educação na Educação Infantil é pensar em proporcionar o aprendizado da maneira mais prazerosa e satisfatória possível, aumentando a segurança da criança e a construção de uma autoimagem e autoestima positiva.

\section{Referências}

BRASIL, Ministério da Educação. Base Nacional Comum Curricular. Brasília: MEC/SEF, 2017.

BROUGÈRE, G. Jogo e Educação. Porto Alegre: Artes Médicas, 1998.

DARIDO, S. C. Educaçáo Física na escola: questóes e reflexôes. Rio de Janeiro: Guanabara Koogan, 2003.

FORTUNA, T. R. O brincar na educaçáo infantil. Revista Pátio: 2003.

GRANDO, R. C. O conhecimento matemático e o uso de jogos na sala de aula. 2000. Tese (Doutorado em Educação) - Faculdade de Educação, Universidade Estadual de Campinas, Campinas.

KISHIMOTO, T. M. (Org.) Jogo, brinquedo, brincadeira e a educaçáo. $7^{a}$ ed. São Paulo. Cortez, 2003. 
MALUF, A. C. M. Brincar: prazer e aprendizado. Petrópolis: Vozes, 2003.

MOYLES, J. R. Só brincar? O papel do brincar na Educação Infantil. Porto Alegre: Artemd, 2002.

PRESTES, Maria Luci de Mesquita. A pesquisa e a construçáo do conhecimento científico: do planejamento aos textos, da escola à academia. 2. ed. rev e atual. e ampl. Sáo Paulo: Rêspel, 2003.

RIZZO, G. A importância do lúdico na aprendizagem com auxílio dos jogos. Rio de Janeiro: Bertrand Brasil, 2001.

SANTIN, S. Educaçáo física: da opressão do rendimento à alegria do lúdico. Porto Alegre: ed. EST/ESEF - UFRGS, 1994.

SANTOS, V. C. de F. F. A organizaçáo do espaço para o brincar na educaçáo infantil numa perspectiva histórico-cultural. Disponível em: <http://www.fateb.br/fateb.cientifica/ downloads/1a_edicao/artigos/009_a_organizacao_do_espaco_para_o_brincar_na_educacao_ infantil.pdf $>$. Acesso em: 02, jan, 2022.

SEBER, M. da G. Psicologia do pré-escolar: uma visáo construtivista. Sáo Paulo: Moderna, 1995.

SOMMERHALDER, A. O lúdico e educaçáo escolarizada da criança: implicaçôes para a prática pedagógica. Revista Paulista de Psicologia e Educação. 2011.

VYGOTSKY, L. S. A formação social da mente. São Paulo: Martins, 1984. 